\title{
PROGESTERONE SYNTHESIS BY PERFUSED BOVINE OVARIES OF EARLY AND LATE PREGNANCY
}

\author{
R. C. MILLS* and M. G. MORRISSETTE $\dagger$ \\ Department of Physiology and Pharmacology, Oklahoma State University, Stillwater, \\ Oklahoma, U.S.A.
}

(Received 23rd June 1969, revised 2nd February 1970)

Summary. Fourteen bovine ovaries of early pregnancy and nineteen of late pregnancy were perfused with citrated bovine blood. During perfusion, the venous blood was collected from each ovary before and after addition of $\mathrm{LH}$ and was analysed for progesterone content. Average progesterone synthesis rates were $4.37 \pm 1.12$ and $4.57 \pm 0.99 \mu \mathrm{g} / \mathrm{min}$ before addition of LH, for ovaries of early and late pregnancy respectively, and increased to $7 \cdot 43 \pm 1.98$ and $7 \cdot 72 \pm 1.33 \mu \mathrm{g} / \mathrm{min}$, respectively, after addition of LH. There was no significant difference in the rates of progesterone synthesis between ovaries of early and late pregnancy at the $5 \%$ level and their response to LH was highly significant $(P<0.01)$. These data indicate that a decrease in progesterone synthesis during late pregnancy in the bovine is not due to a reduction in the ability of the corpus luteum to respond to gonadotrophins.

\section{INTRODUGTION}

Removal of the corpus luteum (CL) during early pregnancy causes immediate abortion in some species, including the cow. However, the CL of the cow may be removed during late pregnancy without causing immediate abortion (McDonald, McNutt \& Nichols, 1953). In experiments by McDonald, et al. (1953) and Estergreen, Frost, Gomes, Erb \& Bullard (1967), it was shown that removal of the bovine GL did not cause immediate abortion but shortened gestation and usually resulted in retained placentae at parturition. Melampy, Hearn \& Rakes (1959) and Gomes, Frost \& Estergreen (1962) reported a lowering of circulating progesterone levels during late pregnancy in the cow. These findings may be interpreted to mean that the quantity of progesterone secreted by the bovine aL during late pregnancy is decreased and no longer critical to the maintenance of pregnancy though adequate for deciduation of the placenta. The experiment reported here was undertaken to determine if this apparent decrease in progesterone secretion was due to a reduction in the ability of the CL to synthesize progesterone in the presence of gonadotrophins. Bovine ovaries of early and late pregnancy were perfused with citrated bovine blood. Proges-

\footnotetext{
* Present address: William Beaumont General Hospital, Department of Medical Research and Development, El Paso, Texas, 79920.

+ Present address: Department of Physiology and Pharmacology, School of Veterinary Medicine, Louisiana State University, Baton Rouge, Louisiana, 70803.
} 


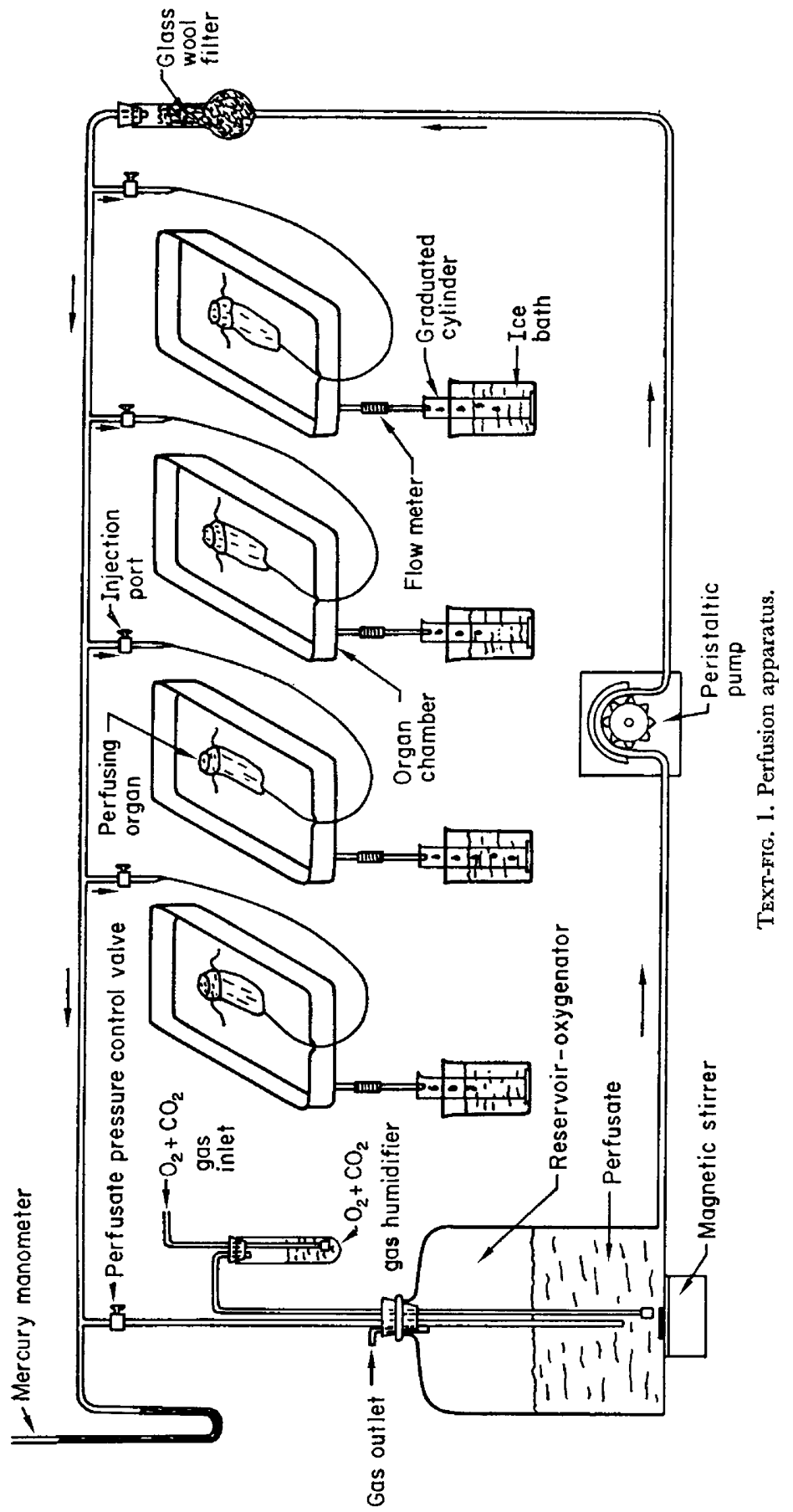


terone synthesis levels in the venous effluents were determined before and after the addition of bovine luteinizing hormone $(\mathrm{LH})$ to the citrated blood.

\section{MATERIALS AND METHODS}

The techniques for the collection, flushing and perfusion of bovine ovaries have been described by Romanoff \& Pincus (1962). The ovaries were collected at an abattoir approximately $40 \mathrm{~min}$ after slaughter of the cows. Each ovary was cannulated and flushed at the abattoir with a cold $\left(12^{\circ} \mathrm{C}\right)$ saline solution and was maintained at this temperature until placed in the perfusion apparatus in the laboratory. The ovaries were perfused four at a time, using an apparatus specially designed for the experiment shown in Text-fig. 1. Organ chambers were made from stainless steel instrument trays covered with plate glass. Each was equipped with a clamp on one end for attachment to a ring stand. A hole was drilled in the opposite end and a glass tube cemented over it to allow collection of the venous effluent. Flow rates were determined from the time required to fill a $1-\mathrm{ml}$ section taken from a $5-\mathrm{ml}$ pipette. Citrated bovine blood was used as the perfusate and perfusion pressure was maintained at $100 \mathrm{~mm}$ $\mathrm{Hg}$. The perfusion temperature was maintained at $37^{\circ} \mathrm{C}$ and a perfusate flow rate of $4.2 \mathrm{ml} / \mathrm{min}$ from each ovary was consistently observed with little variation. Each perfusion of four ovaries contained two ovaries taken from cows at slaughter during the first 3 months of pregnancy (crown to rump length $<15 \mathrm{~cm}$ ) and two ovaries taken from cows at slaughter during the last 2 months of pregnancy (forehead to rump length $>84 \mathrm{~cm}$ ). The venous effluents were collected in $100-\mathrm{ml}$ volumes from each ovary and were chilled immediately on ice. The first $100 \mathrm{ml}$ of venous effluent from each ovary were discarded to allow for an equilibriation period and the two subsequent $100-\mathrm{ml}$ volumes were retained for analysis. After collection of these two samples from each of the four ovaries, bovine $\mathrm{LH}$ (NIH-LH-B4) was added to the citrated blood remaining in the oxygenator-reservoir to attain a concentration of $1 \mu \mathrm{g} / \mathrm{ml}$. The following $100 \mathrm{ml}$ of effluent from each of the ovaries were discarded and the two subsequent $100-\mathrm{ml}$ volumes were retained for analysis. The erythrocytes were removed from all samples and the samples were stored at $-20^{\circ} \mathrm{C}$ for up to 2 weeks until extracted.

Progesterone analyses were performed using techniques modified from those described by Stabenfeldt, Ewing, Patton \& McDonald (1969). The $\left[7 \alpha_{-}{ }^{3} \mathrm{H}\right]$ progesterone $(5.6 \mathrm{~m} \mu \mathrm{c})$ was added to $20 \mathrm{ml}$ of each sample before extraction to allow estimation of losses during extraction. Preparation of derivatives and use of electron capture detection as described by Stabenfeldt et al. (1969) was not necessary as perfused ovarian vein plasma contained ample progesterone for quantification using a less sensitive detector. Following thin-layer chromatography, an aliquot was counted in a Packard Tri-Carb liquid scintillation spectrometer (Series 314E) to determine the recovery of progesterone during the extraction. The scintillation fluid consisted of $4 \mathrm{~g}$ of 2,5-diphenyloxazole (PPO) and $0.3 \mathrm{~g}$ of ( $p$-bis(2-(5-phenyloxazole $)))$-benzene (POPOP) in 1 litre of analytical reagent grade toluene. Another aliquot was injected into a dualcolumn Barber-Coleman Series 5000 gas chromatograph, equipped with 
hydrogen flame detectors to allow quantification of the progesterone. Threefoot glass columns packed with $1 \%$ XE-60 on 80/100 mesh Gas-Chrom Q were used with nitrogen as the carrier gas at a flow rate of $48 \mathrm{ml} / \mathrm{min}$ from each column. The injection port, column bath, and detector temperatures were $255^{\circ}, 220^{\circ}$ and $225^{\circ} \mathrm{C}$, respectively. The mass spectra of the product resulting from the above techniques were determined by direct probe into a LKB-900 mass spectrometer-gas chromatograph. Probe temperature was $30^{\circ} \mathrm{C}$. The average percentage recovery of progesterone using the above techniques was $74 \cdot 58 \pm$ S.E. $1 \cdot 15$.

TABLE 1

PROGESTERONE SYNTHESIZED $\dagger$ BY PERFUSED BOVINE OVARIES OF EARLY AND LATE PREGNANCY

\begin{tabular}{|c|c|c|c|c|c|}
\hline \multicolumn{3}{|c|}{ Early pregnancy* } & \multicolumn{3}{|c|}{ Late pregnancy* } \\
\hline Ovary no. & Pre-LH & Post-LH & Ovary no. & Pre- $L H$ & Post-LH \\
\hline $\begin{array}{r}1 \\
2 \\
5 \\
7 \\
9 \\
10 \\
17 \\
18 \\
22 \\
29 \\
36 \\
37 \\
39 \\
41\end{array}$ & $\begin{array}{r}0.07 \\
0.04 \\
14.03 \\
0.33 \\
6.57 \\
0.90 \\
3.01 \\
5.67 \\
7.74 \\
0.05 \\
7.44 \\
7.74 \\
1.65 \\
5.92\end{array}$ & $\begin{array}{r}0.07 \\
0.22 \\
27.04 \\
1.14 \\
9.18 \\
2.03 \\
5.37 \\
7.32 \\
9.37 \\
0.04 \\
9 \cdot 48 \\
9 \cdot 19 \\
6.92 \\
16.65\end{array}$ & $\begin{array}{r}4 \\
8 \\
11 \\
12 \\
14 \\
15 \\
16 \\
19 \\
20 \\
23 \\
24 \\
31 \\
32 \\
33 \\
34 \\
40 \\
42 \\
43 \\
44\end{array}$ & $\begin{array}{r}5.50 \\
2.43 \\
1.35 \\
1.72 \\
6.56 \\
1.72 \\
0.72 \\
2.34 \\
4.24 \\
6.40 \\
5.86 \\
7.86 \\
0.13 \\
19.40 \\
4.08 \\
5.56 \\
3.17 \\
0.64 \\
7 \cdot 14\end{array}$ & $\begin{array}{r}6.75 \\
4.94 \\
1.02 \\
1.80 \\
7.98 \\
4.00 \\
1.54 \\
13.16 \\
12.64 \\
17.66 \\
17.29 \\
14.06 \\
0.20 \\
15.26 \\
8.56 \\
4.38 \\
7.38 \\
0.55 \\
7.58\end{array}$ \\
\hline Mean \pm S.E. & $4 \cdot 37 \pm 1 \cdot 12$ & $7.43 \pm 1.98 * *$ & Mean \pm S.E. & $4.57 \pm 0.99$ & $7 \cdot 72 \pm 1 \cdot 33^{* *}$ \\
\hline
\end{tabular}

* No significant difference in progesterone synthesis between ovaries of early and late pregnancy.

** Significantly greater $(P<0.01)$ synthesis after the addition of $L H$.

$\uparrow$ Each value is the average of two samples expressed as $\mu \mathrm{g} / \mathrm{min}$.

$\$ 1 \mu \mathrm{g} / \mathrm{ml}$.

\section{RESULTS}

A total of forty-four bovine ovaries was perfused as described above. Of the forty-four perfused ovaries, nine $(20.4 \%)$ failed to synthesize progesterone either before or after the addition of LH and the data from two others were discarded due to losses during progesterone analyses, leaving a total of thirty-three reported here. The average ovarian weights were $10.51 \pm 0.90$ and $11.42 \pm 1.49 \mathrm{~g}$ for early and late pregnancy, respectively, and the average CL weights were $4.12 \pm 0.08$ and $4.47 \pm 0.13 \mathrm{~g}$ for early and late pregnancy, respectively. There was no significant difference between ovarian weights of early and late pregnancy or of CL weights of early and late pregnancy. 
The average amounts of progesterone synthesized per minute by each ovary during the control period and after addition of $\mathbf{L H}$ are shown in Table 1. There was no significant difference between the level of progesterone synthesized by ovaries of early and late pregnancy during the control period or after the addition of LH. However, addition of LH significantly increased $(P<0.01)$ the levels of progesterone synthesis by ovaries of both early and late pregnancy.

\section{DISCUSSION}

The mass spectra of the isolated progesterone compared favourably with the progesterone spectrum reported by Peterson (1962) and provided conclusive evidence that the material isolated and quantified in this study was progesterone. Furthermore, the data reported here provide evidence that in the cow, during late pregnancy, the ovary and CL are capable of responding to LH by secreting progesterone at rates comparable to those of early pregnancy.

Levels of progesterone synthesized in this experiment were slightly greater than those reported by Bartosik, Romanoff, Watson \& Scricco (1967), even though they used three to four times the $1.0 \mu \mathrm{g} / \mathrm{ml}$ level of LH used in this study. However, levels of progesterone synthesis reported by Armstrong \& Black (1966) and Marsh \& Savard (1966) using incubated slice techniques were up to twenty times greater than the levels found in this perfusion study. The difference between the levels of progesterone synthesized by bovine CL using the two different techniques cannot be explained. It should be pointed out that the levels reported here are comparable to the levels in vivo reported by Gomes et al. (1962).

Nine $(20.4 \%)$, six from early and three from late pregnancy, of the forty-four perfused bovine ovaries failed to increase the amount of progesterone in the perfusate either before or after addition of $\mathrm{LH}$. This value, however, is much smaller than the $49.1 \%$ found by Mason, Marsh \& Savard (1962) which failed to respond to LH during a 2-hr slice-incubation study. These results support the postulation of Armstrong \& Black (1966) that conditions of handling of the cows before slaughter, or anaerobic conditions at body temperature for 30 to $40 \mathrm{~min}$ after slaughter before removal of the ovary, greatly influence the ability of bovine CL to synthesize progesterone or respond to LH.

The ovarian or CL weights of early pregnancy were not significantly different from those of late pregnancy. This agrees with the data of Stormshak \& Erb (1961) who found that GL of cows from early pregnancy (16 to 89 days) weighed 5.9 compared with $5.0 \mathrm{~g}$ at mid-pregnancy (90 to 179 days) and $5.5 \mathrm{~g}$ after 180 days of pregnancy.

On the basis of this and previously reported experiments (Melampy et al., 1959; Gomes et al., 1962), it can be postulated that progesterone secretion by the bovine aL diminishes in late pregnancy because of a reduction in levels of circulating gonadotrophins. It can be further postulated that the diminished luteal progesterone of late pregnancy in the bovine must be supplemented by the progesterone synthesized by the placenta (Ainsworth \& Ryan, 1967) and adrenal glands (Balfour, Comline \& Short, 1957). Removal of the ovary during late pregnancy, therefore, removes the prime source of progesterone and the 
maintenance of pregnancy is then dependent on the secondary sources of progesterone, which apparently are not sufficient for normal pregnancy since gestation is shortened and foetal membranes are retained at parturition (McDonald et al., 1953; Estergreen et al., 1967).

\section{ACKNOWLEDGMENTS}

Supported by Grant HD 01088 U.S. Public Health Service, and the Oklahoma Agricultural Experiment Station project 1081.

\section{REFERENCES}

Ainsworth, L. \& RyAN, K. J. (1967) Steroid hormone transformations by endocrine organs from pregnant mammals. II. Formation and metabolism of progesterone by bovine and sheep placental preparations in vitro. Endocrinology, 81, 1349.

ARmstrong, R. T. \& BLACK, D. L. (1966) Influence of luteinizing hormone on corpus luteum metabolism and progesterone biosynthesis throughout the bovine estrous cycle. Endocrinology, 78, 937.

Balfour, W. E., Comline, R. S. \& Short, R. V. (1957) Secretion of progesterone by the adrenal gland. Nature, Lond. 180, 1480.

Bartosik, D., Romanoff, E. B., Watson, D. J. \& Scricco, E. (1967) Luteotropic effects of prolactin in the bovine ovary. Endocrinology, 81, 186.

Estergreen, V. L., JR, Frost, O. L., Gomes, W. R., ERB, R. E. \& Bullard, J. F. (1967) Effect of ovariectomy on pregnancy maintenance and parturition in dairy cows. F. Dairy Sci. 50, 1293.

Gomes, W. R., Frost, O. L. \& Estergreen, V. L., Jr (1962) Progestins in ovarian and peripheral blood of cows during late pregnancy. 7. Dairy Sci. 45, 670 .

MaDonald, L. E., McNutr, S. H. \& Nichols, R. E. (1953) On the essentiality of the bovine corpus luteum of pregnancy. Am. F. vet. Res. 14, 539.

Marsh, J. M. \& SAVARD, K. (1966) Studies on the mode of action of luteinizing hormone on steroidogenesis in the corpus luteum in vitro. 7. Reprod. Fert., Suppl. 1, 113.

Mason, N. R., Marsh, J. M. \& Savard, K. (1962) An action of gonadotropin in vitro. 7. biol. Chem. 237, 1801 .

Melampy, R. M., Hearn, W. R. \& Rakes, J. M. (1959) Progesterone content of bovine reproductive organs and blood during pregnancy. F. Anim. Sci. 18, 307.

Peterson, L. (1962) Mass spectra of some highly substituted pregnanes and pregnenes. Analyt. Chem. 34, 1781 .

Romanoff, E. B. \& Pincus, G. (1962) Studies of the isolated perfused ovary: Methods and examples of application. Endocrinology, 71, 752.

Stabenfeldt, G. H., Ewing, L. L., Patton, J. P. \& McDonald, L. E. (1969) Gas-liquid chromatography for estimation of peripheral plasma progesterone in domestic animals. F. Endocr. 44, 23.

Stormshak, F. \& ERb, R. E. (1961) Progestins in bovine corpora lutea, ovaries and adrenals during pregnancy. F. Dairy Sci. 44, 310. 